\title{
Current Concept of Selective Nek Dissection
}

\author{
H. Hakan Coskun \\ Uludag University School of Medicine, Department of Otolaryngology \\ Turkey
}

\section{Introduction}

It has long been known that the most important prognostic factor of squamous cell carcinoma of the head and neck is the presence of cervical lymph node metastasis. When neck metastases are not managed properly, this will result a decrease the patient's chance of survival. Radical neck dissection has been introduced in the beginning of 1900's as the surgical procedure to remove cervical lymph nodes systematically in an effort to address metastases and been used widely since then. But radical neck dissection was associated with significant morbidity and especially patients with clinically negative neck were suffering from this unnecessary morbidity. Almost 60 years after introduction of radical neck dissection, Suarez (Ferlito \& Rinaldo, 2004) presented modified radical neck dissection (often termed as functional neck dissection). Though, the morbidity associated with neck dissection had been reduced by modified radical neck dissection, efforts to further reduce the morbidity continued and in 1985, Byers (Byers, 1985) reported removal of the cervical lymph node levels which are at the greatest risk for metastasis in patients with clinically negative neck, a surgical procedure which will later be called "selective neck dissection" (Robbins et al, 1991). The rationale behind selective neck dissection is removal of certain lymph node groups, which are at risk for occult metastasis, while preserving the functional structures of the neck and the lymph node groups that are not likely to contain metastasis, in an effort to reduce the risk of complications and morbidity associated with neck dissection.

The current and widely used classification of neck dissections has been introduced by a group of authors from the American Head and Neck Society and American Academy of Otolaryngology-Head and Neck Surgery in 2002 (Robbins, 2002). According to this classification, SND refers to selective neck dissection and the removed lymph node groups are depicted in brackets. For example selective neck dissection involving levels II to IV is recorded as SND (II-IV). The committee also recommended the extent of dissection for each anatomic sub-site. For oral cavity cancer, the recommended procedure was SND (I-III), which was formerly called as supraomohyoid neck dissection. It was noted that level IV might be involved in patients with oral tongue cancer and SND (I-IV), which was formerly called as extended supraomohyoid neck dissection, may be warranted in these patients. The recommended procedure for oropharyngeal, hypopharyngeal and laryngeal cancers was SND (II-IV), which was formerly called lateral neck dissection. The committee noted that level IIB involvement was rare in laryngeal and hypopharyngeal cancers, thus SND (IIA,III,IV) would be sufficient, however removal of level IIB was recommended for 
oropharyngeal cancers. It was also noted that retropharyngeal lymph nodes needed to be addressed for hypopharyngeal cancers. The committee's recommendation for cancer of the midline structures of the anterior lower neck, such as thyroid cancer, advanced glottic and subglottic larynx cancer, advanced piriform sinus cancer, and cervical esophageal/tracheal cancer, was SND (VI), which was formerly called central neck dissection, with or without dissection of other levels. The recommendation for cutaneous malignancies was tailoring the extent of dissection according to the location of the primary tumor.

Recently, the members of International Head and Neck Scientific Group proposed a new classification for neck dissection (Ferlito, 2011). According to this new classification, ND refers to neck dissection and the removed structures and neck levels are depicted in brackets. For example ND (I-V, SCM, IJV, CN XI) is radical neck dissection, ND (II-IV) is lateral neck dissection. The best advantage of this classification is that any modification of neck dissection can be depicted. For example removal of a non-lymphatic structure during a selective neck dissection can be depicted with this classification, which was not possible with previous classifications.

In the last twenty years, it has been recognized that even after selective neck dissections, patients suffer from some degree of morbidity, such as shoulder dysfunction and chylous fistula. Recently, neck dissections more limited than classical selective neck dissections have been introduced and been advocated by many authors to further reduce the morbidity of neck dissections.

\section{Extent of surgical removal for selective neck dissection}

The extent of neck dissection is a major debate for the last years because limiting the dissection may help to reduce morbidity, avoid complications and reduce operative time, but this has to be done without reducing the efficacy of neck dissection. For clinically N0 or $\mathrm{N} 1$ head and neck cancers of various primary sites, radical neck dissection is considered as an overtreatment, because the three functionally important non-lymphatic tissues that are removed during radical neck dissection, the internal jugular vein, spinal accessory nerve and sternocleidomastoid muscle, are rarely involved in the early stages of the neck disease. Furthermore, in N0 and some N1 head and neck cancers, a modified radical neck dissection is also considered unnecessary, because each head and neck site has a well-known lymphatic drainage pathway and metastases outside these pathways are very rare. Thus, only the lymph node levels that are at the highest risk for metastasis are removed and the other levels are left undissected in order to decrease operative morbidity. Today, efforts to improve the functional results of neck dissection are continuing and a new concept of more limited neck dissection is emerging.

\subsection{Selective neck dissection for squamous cell carcinoma of the head and neck 2.1.1 Selective neck dissection for oral cavity cancer}

The management of oral cavity cancer with clinically N0 neck varies considerably. It has been clearly demonstrated that occult metastases may occur in up to $20-44 \%$ (Po Wing Yuen, 2002; Fakih, 1989; Jones, 1992; Kligerman, 1994; Sheahan, 2003; Spiro, 1986; Woolgar, 1999; Ross, 2004; Sparano, 2004) of these patients. This finding supports the need for an elective neck dissection but there are still surgeons who prefer the observation policy reserving neck dissection for regional recurrence. In a recent article, Fasunla et al (Fasunla, 2011) reported the results of a meta-analysis comparing elective neck dissection versus 
observation in clinically N0 oral cavity cancer. They have found that elective neck dissection reduced the rate of disease-specific death. Obviously, elective neck dissection offers a better outcome in terms of survival, but results in unnecessary morbidity in patients who do not have occult metastases. Thus we need to identify the patients who are more likely to have occult metastases and need elective neck dissection. Studies aiming to identify the rate of occult metastases in relation to various risk factors have shown that tumor thickness (depth of tumor invasion) is a very important factor. Though the tumor thickness measurement methods or tumor-thickness cut-off levels vary considerably among studies, uniformly all studies reported that tumors with a thickness of more than a certain level (ranges from 2 to $10 \mathrm{~mm}$, in most studies 4 or $5 \mathrm{~mm}$ ) are more likely to develop occult metastases (Pentenero, 2005). According to the author of this chapter's experience, almost all patients present with tumors thicker than 4 or $5 \mathrm{~mm}$, thus almost all patients require elective neck dissection.

Though there is general agreement on elective management of the neck, debate continues on the extent of surgery. Many studies have shown that comprehensive (i.e. level I-V) neck dissections result in unnecessary overtreatment. In a prospective multi-institutional study from Brazil (Brazilian Head and Neck Cancer Study Group, 1998), it has been shown that both modified radical and supraomohyoid neck dissections can offer comparable survival and recurrence rates in treatment of clinically $\mathrm{N} 0$ oral cavity cancer.

An ideal neck dissection for clinically N0 neck should remove all the lymph node groups, which potentially harbor occult metastases while preserving the non-lymphatic structures along with the lymph node groups that are unlikely to contain occult metastases. It has been demonstrated that level V is rarely involved in oral cavity cancers (Dias, 2006). Furthermore, these rare metastases to level $\mathrm{V}$ occur only when other levels are involved and isolated metastasis to level V never happens (Dias, 2006). It has been well-known that levels I,II and III are the most frequently involved levels in oral cavity cancers and removal of these lymph node groups through a level I-III neck dissection (supraomohyoid neck dissection) has been the standard treatment of clinically N0 oral cavity cancer. However, extension of level I-III neck dissection to include level IV (extended supraomohyoid neck dissection) or removal of level IIB is still debatable.

The significance of level IV metastases without involvement of other levels (i.e. skip metastases) is yet to be known. Some authors have demonstrated that rate level IV metastases are high enough to warrant dissection of this level, with a metastasis rate of $15 \%$ (De Zinis, 2006, Byers, 1997). Also, Woolgar (Woolgar, 2006) demonstrated that an important proportion of neck recurrences occurred because of skip metastases to levels III or IV, which is a finding that supports extended supraomohyoid neck dissection for prevention of neck recurrences. On the other hand, there are various reports that demonstrate a low incidence of metastases in level IV (Mishra, 2010, Bajwa 2011). These authors have concluded that extension of dissection to include level IV did not offer an advantage for prevention of neck recurrences and level I-III dissection should be the preferred surgical procedure for management of clinically N0 oral cavity cancer (Bajwa, 2011). In the light of the current literature, the management of level IV is not clear in clinically N0 oral cavity cancer; further prospective and multi-center studies are needed.

Studies have shown that metastases to level IIB from oral cavity cancers are rare, occuring at a mean rate of $6 \%$ (Paleri, 2008, Lea, 2010). It has been demonstrated that isolated level IIB metastases from oral cavity cancers are exteremely rare (Lea, 2010). But, when other levels, especially level IIA, contain occult metastases, level IIB metastases may occur in up to $22 \%$ of the patients (Elsheikh, 2005, Lea, 2010). Interestingly, level IIB metastases are almost 
always seen in patients with tongue cancer, however other oral cavity primary sites only rarely give rise to level IIB metastases (Elsheikh, 2005, Lea, 2010). When the lesion is located in the retromolar trigone with extension to the anterior pillar, level IIB should be dissected (Ayad, 2009). Although the current literature demonstrates that level IIB metastases from oral cavity cancers are rare, there is not enough evidence to support preservation of level IIB. Prospective, multi-center studies utilizing standardized surgical dissection and specimen processing techniques are required.

Razfar et al (Razfar, 2009), have shown that submandibular gland is rarely involved in early stage (stage I-II) oral cavity cancers and the gland can be preserved during selective neck dissections. It is true that the submandibular gland is not a lymphatic tissue and unless it is directly invaded by the disease, it does not contain malignant disease. However, there are many lymph nodes in the close vicinity of the gland, which are the first echelon lymph nodes of oral cavity. Thus, one should be very carefully remove all the level I lymph nodes while preserving the gland. The gland should not be preserved if the arterial or venous circulation of the gland is damaged or when post-operative radiotherapy is likely.

\subsubsection{Selective neck dissection for Laryngeal cancer}

In the intrauterine life, glottis and subglottic larynx is derived from tracheobronchial bud, which develops from the sixth branchial arch and is formed by the union of lateral furrows on each side of the tracheobronchial bud. Supraglottic larynx is derived from buccopharyngeal bud, which develops from third and fourth branchial arches without a midline union. Blood and lymph vessels develop along with these compartments. So, supraglottic and glottic-sublottic compartments have different lymphatic drainage pathways. Supraglottic larynx drains bilaterally into the upper and middle jugular lymph nodes, whereas glottic and subglottic regions drain into lower jugular, prelaryngeal and pretracheal lymph nodes. Supraglottic larynx has a rich lymphatic network and metastasis can occur even in the early stages of cancer, however vocal folds have sparse lymphatic channels, so metastases from early glottic lesions are rare (Armstrong, 1995). This basic knowledge provides a basis for planning of neck dissection in relation to the primary tumor. Lateral neck dissection (SND II-IV) has been used widely in the past twenty years for management of the neck in clinically N0 laryngeal cancer because it has been demonstrated that metastases of laryngeal cancer usually occurs in these levels and levels I and V are rarely involved (Robbins, 2002, Kowalski, 1995, Jones, 1994, Ferlito, 2001). SND II-IV is very effective in treating occult metastases and in a previous study from the author of this chapter's department, it has been demonstrated that a neck recurrence rate as low as $1.7 \%$ can be achieved after SND II-IV (Erisen, 2001).

Although SND provides excellent oncological results, functional outcome after SND II-IV is not as good as expected. A prospective study from the author of this chapter's department has demonstrated that there is dysfunction of the spinal accessory nerve after SND (Erisen, 2004). Koybasioglu et al (Koybasioglu, 2000) have also shown that spinal accessory nerve function is impaired after SND. The most possible reason of dysfunction is retraction of the spinal accessory nerve during clearance of sublevel IIB. Numerous studies have shown that the incidence of metastasis in sublevel IIB is very low. In the prospective studies, including one study by the author of this chapter, analyzing the rate of sublevel IIB metastasis in patients with clinically N0 laryngeal cancer, rate of metastasis ranged between $0 \%$ and 3,2\% (Koybasioglu, 2002, Aydogan, 2004, Coskun, 2004, Lim, 2006, Elsheikh, 2006, Paleri, 2008). In these studies, there was no isolated sublevel IIB metastasis and metastases in sublevel IIB 
were always associated with sublevel IIA metastases. Rinaldo et al (Rinaldo, 2006) reviewed the results of these studies and concluded that dissection of sublevel IIB is not indicated in patients with clinically N0 laryngeal cancer. The authors have concluded that spinal accessory nerve dysfunction can be minimized without reduction in the oncological safety of the neck dissection by this way. After oncological safety of level IIB preserving selective neck dissection for clinically N0 laryngeal cancer has been demonstrated, a prospective study to analyze the functional outcome of this approach was performed in the author of this chapter's department (Celik, 2009). According to the results of this study, none of the 30 patients who underwent sublevel IIB preserving selective neck dissections for clinically N0 laryngeal cancer developed shoulder syndrome in the post-operative period.

The necessity of dissection of level IV in patients with clinically N0 laryngeal cancer has been questioned recently. Dissection of level IV is not without complications, chylous fistula and phrenic nerve injury may occur. In a previous study by the author of this chapter revealed no metastasis in level IV of 113 neck dissection specimens collected from 71 patients with clinically N0 laryngeal cancer (Coskun, 2004). Elsheikh et al performed a prospective study and evaluated metastasis by pathological and molecular analysis is 31 patients with clinically N0 laryngeal cancer. The authors found only one metastasis in level IV $(3,2 \%)$ in a patient with a T3N0 transglottic cancer (Elsheikh, 2006). The studies regarding metastases to level IV in patients with clinically N0 laryngeal cancer were later reviewed by Elsheikh et al (Elsheikh, 2006) and the authors have concluded that level IV metastases are rare in clinically N0 laryngeal cancer. But the authors have stressed that the larynx is divided into three compartments, which have different lymphatic drainage pathways and the extent of dissection should be individualized according to the location of the primary tumor. The final conclusion was that dissection of level IV might not be indicated in patients with glottic or supraglottic tumors but transglottic or subglottic tumors might well require level IV dissection.

Based on the observations from prospective studies regarding level IIB and level IV metastases in patients with clinically N0 laryngeal cancer, Ferlito et al (Ferlito, 2008) suggested level IIA-III dissection in patients with glottic and supraglottic cancers with clinically N0 neck. This approach appears to be the current treatment of choice.

Recently, Medina et al (Medina, 2011) performed a comprehensive review about central compartment dissection in laryngeal cancer. The authors have found evidence that level VI metastases were frequent in patients with primary subglottic carcinomas, advanced glottic and advanced supraglottic carcinomas and recommended elective treatment of level VI in these patients. In such patients, selective neck dissection should be extended to include level VI.

In summary, carcinomas arising from different compartments of the larynx have different patterns of lymph node metastasis. Current literature supports level IIA, III dissection is early supraglottic and glottic cancers. Level IV dissection is required in transglottic, primary subglottic cancers and glottic cancers with subglottic extension. Dissection should be extended to include level VI in patients with primary subglottic carcinomas, advanced glottic and advanced supraglottic carcinomas.

\subsubsection{Selective neck dissection for oropharyngeal and hypopharyngeal cancer}

Elective treatment of the neck in patients with oropharyngeal or hypopharyngeal cancer is not as clear as oral cavity or larynx. First of all, oropharyngeal and hypopharyngeal cancers are rare, as compared to oral cavity or laryngeal cancers and there is less data in the 
literature regarding the distribution of occult metastasis of these cancers. Second, in the past few decades, treatment of oropharyngeal and hypopharyngeal cancers has shifted from surgery to chemoradiation in many centers, reserving surgery for salvage. The reasons for this shift are the high sensitivity of these cancers to chemoradiation and the functional losses associated with surgery. Obviously there are patients who are not good candidates for chemoradiation or whose tumors can be managed with function preserving surgery but an important proportion of these patients receive non-surgical treatments. So, it is difficult to make conclusions about elective management of the clinically N0 neck in patients with oropharyngeal and hypopharyngeal cancer.

Oropharyngeal cancers usually drain into level II, III and IV lymph nodes, as well as retropharyngeal and parapharyngeal lymph nodes (Ferlito, 2006). In patients with clinically N0 oropharyngeal cancer level II-IV dissection would be appropriate. Paleri et al (Paleri, 2008) found metastases in level IIB of 5 patients in a group of 96 patients $(5,2 \%)$ with clinically N0 oropharyngeal cancer. Similarly, Villaret et al (Villaret, 2007) reported that two metastases in level IIB in 32 neck dissection specimens $(6 \%)$ of patients with oropharyngeal cancer. Lodder et al (Lodder, 2008) found only one metastasis (1\%) in level IV in specimens of 92 selective neck dissections for oropharyngeal cancer. These findings reflect that a more limited dissection confined to levels IIA and III may be appropriate, as is the case in oral cavity cancers, but more prospective studies with higher number of patients are required.

Pyriform sinuses drain into the jugulodigastric lymph node and to the midjugular and spinal accessory chains. Inferior portion of the hypopharynx and postcricoid region drain into the paratracheal and paraesophageal nodes and to nodes in the supraclavicular fossa. Posterior hypopharyngeal wall drain into the retropharyngeal nodes and to the midjugular chain (Uppaluri \& Sunwoo, 2010). In 1990 Candela et al (Candela, 1990) reported the analysis of neck dissection specimens of 333 patients with oropharyngeal or hypopharyngeal cancers. They found that levels II, III and IV were most frequently involved and isolated skip metastases out of these levels occurred only in one patient $(0,3 \%)$. The authors have concluded that their data supports selective neck dissection in patients with clinically N0 neck. Weber et al (Weber, 1993) examined paratracheal dissection specimens of patients with larynx, hypopharynx and cervical esophagus cancers and found paratracheal metastases in three of 36 patients $(8,2 \%)$ with hypopharyngeal primaries. In conclusion, paratracheal lymph node dissection along with levels II, III and IV appears to be the appropriate management in patients with clinically N0 hypopharyngeal cancer.

\subsubsection{Selective neck dissection for squamous cell carcinoma of other head and neck primary sites}

There is insufficient data regarding selective neck dissection for squamous cell carcinoma of other head and neck primary sites, such as paranasal sinuses, nasopharynx, skin, etc.

The routine management of recurrent or residual neck disease after radiotherapy (or chemoradiation) in patients with nasopharyngeal carcinoma has been radical neck dissection for many years. Recently, Zhang et al (Zhang, 2011) reported their experience with recurrent or residual regional metastases of nasopharyngeal carcinoma. Patients with residual disease had a better outcome than the patients with recurrent disease. There were 70 patients with residual neck disease and 42 of these patients one single persistent lymph node during the course of the treatment. Though the researchers had performed radical neck dissection in every case, they have concluded that residual disease limited to one single lymph node might be managed with selective neck dissection. 
Ebrahimi et al (Ebrahimi, 2010) analysed the distribution of lymph node metastases in 295 neck dissection specimens of 282 patients with cutaneous squamous cell carcinoma of the head and neck. According to the distribution of metastases, they concluded that selective neck dissection including level I-III for facial primaries, level II-III for anterior scalp and external ear primaries, and levels II-V for posterior scalp and neck primaries would be appropriate.

\subsection{Selective neck dissection for malignant tumors of the head and neck other than squamous cell carcinoma}

2.2.1 Selective neck dissection for malignant salivary gland tumors

Management of clinically N0 neck in patients with malignant salivary gland tumors is controversial. Because of the relative rarity of these tumors and the high variability in clinical behavior of different histopathological tumor types, which are very high in number, it is difficult to draw conclusions. Armstrong et al (Armstrong, 1992) found occult metastases in 34 of the 90 (38\%) of the patients with clinically N0 salivary gland cancer who underwent elective neck dissection. Some authors (Armstrong 1992, Spiro 1986, Yu 1987) have found evidence that the risk of metastasis is related to the site of the primary tumor, with submandibular gland having the highest risk for metastasis followed by parotid and minor salivary gland tumors. Some histopathological types including undifferentiated carcinoma, squamous cell carcinoma, high-grade mucoepidermoid carcinoma, adenocarcinoma NOS, carcinoma ex pleomorphic adenoma, and salivary duct carcinoma are also associated with a higher incidence of occult metastasis (Armstrong 1992, Yu 1987, Bhattacharya 2002, Regis De Brito Santos 2001, Ferlito 2001). Armstrong et al (Armstrong, 1992) found that high-grade tumors had a high risk of occult metastases (49\%) compared to low grade or intermediate tumors (7\%). Recently, experience of a single institution from Japan about elective neck dissection in 77 patients with carcinoma of the parotid gland has been reported (Kawata, 2010). Lymph node metastases were found in $61,3 \%$ and $22,9 \%$ of the patients with high-grade and intermediate-grade tumors, respectively. There was no metastasis from low-grade tumors. 51 patients were initially staged as clinically N0 and 8 of these patients had occult metastases on histopathologic examination $(15,7 \%)$. The authors had performed modified radical neck dissection for high-grade tumors and selective neck dissection (level I-III and VA) for other tumors, in this group of 51 patients with clinically negative neck, but the outcome after treatment was not reported. Of note, the accuracy of preoperative fine needle aspiration cytology of the parotid tumor was low (46,5\% overall), especially in patients with intermediate or low-grade tumors $(32,5 \%)$. Thus the authors recommended elective neck dissection in every patient with N0 malignant parotid tumor owing to the low accuracy of pre-operative diagnosis.

Based on these observations, it can be concluded that elective neck dissection is indicated in patients with high grade tumors, submandibular gland tumors and tumors of certain histopathologic type with clinically N0 neck. But owing to the low accuracy of preoperative fine needle aspiration cytology, elective neck dissection may well be indicated in every patient with clinically N0 malignant salivary gland tumor.

Extent of elective neck dissection is not clear in patients with clinically N0 salivary gland cancer. For parotid tumors, selective neck dissection of levels I-IV (or I-III plus VA, Kawata, 2010) and for submandibular and sublingual gland tumors dissection of levels I to III is recommended (Armstrong, 1992; Gold, 2005). 


\subsubsection{Selective neck dissection for thyroid cancer}

Thyroid cancers are a heterogeneous group with different clinical behaviour but management of the neck is important for almost all types of thyroid cancer. The American Head and Neck Society and American Academy of Otolaryngology-Head and Neck Surgery have recommended Central (level VI) neck dissection with or without dissection of other levels for thyroid cancer (Robbins, 2002). However, there is still debate on the extent of the nodal dissection for optimal outcome.

Papillary thyroid carcinoma, which is one of the most common cancers of the human body, is the most common thyroid malignancy. Though the level VI lymph nodes are the first echelon nodes for papillary carcinoma, lateral metastases are also very common. Occult lateral metastasis rate was $55 \%$ in a study $(\mathrm{Lim}, 2011)$ and lateral metastases were associated with primary tumor size and the number of metastatic central lymph nodes. Recently, Patron et al. (Patron, 2011) reported a much lower rate of lateral metastases $(18,6 \%)$ in a group of 131 patients with papillary thyroid carcinoma. In this series, metastasis rate was $2,9 \%$ in level IIB and $0 \%$ in level VA, thus the authors recommended dissection of levels IIA, III, IV and VB for papillary thyroid carcinoma with clinically negative neck. In contrast, Vayisoglu et al (Vayisoglu, 2010) found metastases in 22 of 47 neck dissections (46,8\%) and incidence of the lateral metastases was much higher. Levels II, III, IV and V were involved in $12.7 \%, 25.5 \%, 38.2 \%$, and $8.5 \%$ of the specimens respectively. Level IIB metastases were also very rare in this study (one of 47 neck dissections, 2,1\%) and the authors have concluded that level IIB might be left undissected in selective neck dissections for papillary thyroid carcinoma.

Medullary carcinoma is an aggressive form of thyroid cancer. Rate of lymph node metastasis is much higher in medullary carcinoma. Oskam et al (Oskam, 2008) found lymph node metastases in $91 \%$ of the ipsilateral neck dissection specimens, $91 \%$ of the paratracheal dissections and $63 \%$ of the contralateral dissections. There were metastases in five of the twelve elective neck dissection specimens. High number of positive lymph nodes was associated with a poor prognosis. Dissection of levels II-V accompanied with central dissection is recommended in every patient with medullary carcinoma.

\subsubsection{Selective neck dissection for head and neck melanoma}

Malignant melanoma is another rare tumor of the head and neck region with a very poor prognosis. Clinically apparent metastases of melanoma are treated with comprehensive neck dissection, however there is no consensus on how to treat the occult metastases. There are reports about sentinel node studies but the extent of dissection is not clear. Current literature supports comprehensive neck dissections rather than selective dissections, in order to achieve better regional control and adjuvant radiotherapy for patients with two or more involved lymph nodes (Hamming-Vrieze, 2009).

\subsection{Selective neck dissection for clinically positive neck}

The widely accepted management of clinically positive neck has been radical or modified neck dissection for several decades. Recently, some investigators have found strong evidence that selective neck dissection may be used for carefully selected patients with clinically positive necks. Andersen et al (Andersen, 2002) reported the results of 129 selective neck dissections in 106 patients with previously untreated head and neck cancer and clinically positive neck. They obtained a regional control rate of $94,3 \%$ with six 
recurrences in the operated side of the neck that had undergone selective neck dissection. Kowalski and Carvalho (Kowalski \& Carvalho, 2002) retrospectively analyzed radical neck dissection specimens of 164 patients with oral cavity cancer and clinically N1 or N2a neck. They found only one metastasis in level IV $(0,6 \%)$ and none at level V. They also noted a high false positive rate $(57,4 \% \mathrm{pN} 0)$ in N1 patients with the clinically positive node in level I. The authors have concluded that supraomohyoid neck dissection may be used instead of radical neck dissection in patients with clinically N1 neck in level I. More recently Santos et al (Santos, 2006) reported their results of 34 selective neck dissections performed on 28 patients with clinically $\mathrm{N}+$ head and neck cancer. They had four recurrences $(11,8 \%)$ after selective neck dissection. One of these patients was N1, two were N2b and one was N2c. Three of these patients had T4 tumors and one had T3 tumor. Researchers from University of Pittsburgh (Simental, 2006) performed a retrospective analysis of 65 patients with clinically $\mathrm{N}+$ head and neck cancer who underwent selective neck dissection. There were 8 recurrences $(12,3 \%)$, four of them occurred outside the field of dissection and four recurrences $(6,1 \%)$ occurred in the field of dissection. Four recurrences could be managed by salvage surgery with a resultant overall regional control rate of $93,9 \%$. In this series, 21 of the 65 cases $(\% 32)$ who were staged clinically $\mathrm{N}+$ did not have metastasis on pathological examination.

In a recent study (Dhiwakar, 2010), it has been reported that selective neck dissection can be used to treat clinically positive neck with involvement of non-lymphatic structures, especially if the nodal disease was confined to two or less neck levels. The authors were able to obtain a recurrence rate of $0 \%$ for primary treatment cases and $13 \%$ for post-radiation cases. Though these results are very encouraging, this is the only study reported in this specific group of disease and needs to be supported with further studies.

It should be noted the two of the studies mentioned above (Santos, 2006; Simental, 2006) reported relatively high rates of regional failure and reflect undertreatment in these patients. Obviously an important proportion of patients with clinically $\mathrm{N}+$ neck do not have metastasis on histopathological examination and any neck treatment would be an overtreatment for these patients, but a balance between overtreatment and undertreatment should be implemented. Based on the observations from the current literature, it appears that selective neck dissection is feasible in some carefully selected patients with clinically positive neck. However, more prospective and primary site-specific studies with larger number of patients are needed to identify which patients with clinically $\mathrm{N}+$ neck are good candidates for selective neck dissections.

\subsection{Selective neck dissection after primary chemo-radiation for head and neck cancer}

Planned radical neck dissection for initially positive neck after completion of primary chemo-radiation, regardless of the initial stage and response of the neck disease was the treatment of choice in the first years of the age of organ preservation. In the following years, there has been a consensus that planned neck dissection in patients who initially present with N1 neck disease is not necessary. However, debate continues about routine performance of planned neck dissection for patients who present initially with bulky $(\geq \mathrm{N} 2)$ neck disease. Recently Ferlito et al (Ferlito, 2010) reviewed the literature to evaluate the necessity of planned neck dissection after complete response to chemo-radiation. The authors have found 24 articles in favour of benefit of planned neck dissection and 26 articles that do not demonstrate an advantage of planned neck dissection. The authors have 
concluded that use of planned neck dissection for patients with a complete response to chemo-radiation cannot be justified.

Nowadays, it has been demonstrated that selective neck dissection is possible in some of these patients. Langerman et al (Langerman, 2009) performed 43 neck dissections on 34 patients after completion chemo-radiotherapy. All patients had N2 or greater disease before treatment and 39 of the 43 neck dissections (91\%) performed were selective neck dissections. In this study post-treatment computed tomography was used to determine the extent of neck dissection and was found to be helpful. More recently, Dhiwakar (Dhiwakar, 2011) reported their results of selective neck dissection performed for persistent neck disease following chemoradiation. Sixty-nine selective neck dissections were performed on 62 patients and only one recurrence was observed. Another study supporting selective neck dissection after chemo-radiation was presented by Cannady et al (Cannady, 2010). The authors have demonstrated that SND would remove residual disease in most cases when the dissection would encompass the next distal level with the original levels.

In summary, the current literature does not support planned neck dissection after complete response to chemo-radiation. In the case of persistent neck disease, selective neck dissection is feasible in the majority of the cases.

\subsection{Surgical technique of selective neck dissection}

The first step of selective neck dissection is the skin incision. In most instances, neck dissection is performed along with a primary tumor removal and an incision, which allows primary tumor removal and neck dissection is preferred. If the plan is to perform a laryngectomy with bilateral neck dissections a " $U$ " shaped incision is used to create an apron flap. In other instances, the author of this chapter prefers a "MacFee incision". In most instances a single horizontal incision placed at the level of thyroid notch or cricoid cartilage allows removal of all lymph node groups, but occasionally two incisions, one at the level of the hyoid bone and one $2-3 \mathrm{~cm}$ above the clavicle, may be necessary. Especially if removal the primary tumor requires a lip split incision, two horizontal incisions are used and the upper incision is combined with the lip split incision. For a unilateral neck dissection the incision extends from a point $3-4 \mathrm{~cm}$ posterior to the sternocleidomastoid (SCM) muscle to a point on the 3-4 $\mathrm{cm}$ other side of the midline. For bilateral neck dissection, the incision extends 3-4 cm posterior to the SCM on each side. The superior and inferior skin flaps are elevated in a subplatysmal plane to allow exposure of the border of the mandible superiorly and the clavicle inferiorly. If level IV will not be dissected, elevation of the inferior flap down to the level of cricoid cartilage is sufficient. After the skin flaps are elevated, the superficial layer of the deep cervical fascia overlying the submandibular gland is incised at the inferior border of the gland and elevated as a second layer up to the level of the border of the mandible in order to protect the marginal mandibular branch of the facial nerve, which lies within this fascia.

Next, the investing layer of the deep cervical fascia is incised along the anterior border of the SCM. Fascia on the lateral surface of the SCM must be protected, not peeled off. This fascia prevents scar formation and adhesion of the SCM to platysma and overlying skin. Preservation of the fascia may help to reduce post-operative shoulder pain. The external jugular vein may need to be divided and ligated at the level of angle of the mandible but it is better protected whenever possible. The SCM is retracted laterally and posteriorly while the fibro-fatty tissue of the anterior triangle of the neck is retracted medially, allowing an easy 
dissection during clearance of levels II, III and if necessary level IV along the anterior and medial surface of the SCM. As the fibro-fatty tissue is peeled off the SCM, the spinal accessory nerve (SAN) comes into view in the junction of upper and middle thirds of the SCM. For easier dissection at level II, the investing layer of the deep cervical fascia is divided at the inferior border of the posterior belly of the digastric muscle and the muscle is retracted medially and superiorly for a good exposure. Then the fibro-fatty tissue overlying the spinal accessory nerve is dissected off the nerve up to the skull base. This is done by opening up the tissues with a fine tipped haemostat and cutting the tissues with a scalpel. After the nerve is traced up to the skull base, all the fibro-fatty tissue should be cut with a scalpel down to the fascia of deep neck muscles along the course of the nerve. Very rarely, internal carotid artery may be tortuous at this level mimicking a lymph node and causing a big danger. The fibro-fatty tissue posterior to the SAN is level IIB and after freeing from the surrounding structures, this tissue is passed under the SAN and brought into level IIA. However, this manoeuvre requires traction of the SAN, which may result in dysfunction of the nerve. It is better to remove level IIB separately and continue with dissection of level IIA without traction of the SAN. Dissection is continued along the posterior border of SCM to the inferior extent of dissection, either to clavicle or the tendon of the omohyoid muscle. Traction of the SCM should be minimized. Pulling the fibro-fatty tissue medially with haemostats placed in multiple points and retracting the SCM laterally with gauze hold by the primary surgeon's left hand can achieve a good exposure. During this dissection, branches of the cervical plexus are encountered and protected. The first three roots give fibers to the spinal accessory nerve and cutting these roots cause dysfunction of the nerve. Also preservation of the cervical roots prevents numbness of the neck skin and may help to reduce shoulder pain.

After the dissection along the posterior border of the SCM is completed, the fibro-fatty is grasped from several points with haemostats and pulled in a lateral and anterior direction by an assistant. In an "en bloc" fashion, all the fibro-fatty tissue is dissected over the branches of the cervical plexus in an anterior direction using a scalpel. Sharp dissection continues over the carotid sheath but care is taken not to injure the carotid artery, the vagus nerve and the internal jugular vein. The internal jugular vein is very fragile and must never be hold with an instrument with sharp teeth. The vein has many branches along its course and all these branches need to be clamped and suture ligated. Also every effort should be made to visualize and protect the lymphatic duct in level IV, which is constantly present on the left side and frequently present on the right side of the neck. The fibro-fatty tissue lying medial to the carotid sheath is dissected to the lateral border of the strap muscles, which is the medial border of dissection. Care must be taken to protect the superior laryngeal nerve at this point.

If level I is to be dissected, dissection continues upward. The medial border of the anterior belly of the opposite digastric muscle and the inferior border of the mandible are the borders of level I dissection. The fibro-fatty tissue is grasped with haemostats in several points and cleared over the underlying muscles. In most instances the submandibular gland is removed along with the fibro-fatty tissue. Although the gland is almost never involved with disease and there are authors who recommend preservation of the gland, to assure a complete removal of all submandibular lymph nodes excision of the gland is usually required. All the fibro-fatty tissue down to the mylohyoid muscle must be cleared.

During the whole dissection, use of mono-polar cautery should be minimized in order to avoid heat damage to the nerves in the surgical field. Bi-polar cautery should be used whenever haemostasis is necessary. 
After completion of dissection two vacuum drains, one anterior to the carotid sheath and one posterior to the sheath are placed and secured. Subcutaneous layer and skin is closed in the usual fashion.

\section{Conclusion}

Presence of cervical lymph node metastases is one of the most important prognostic factors of head and neck cancer. Since the first introduction for more than 100 years ago, neck dissection has been the main treatment of clinically apparent or occult lymph node metastases. Through decades, the procedure of neck dissection has undergone an evolution. Today, neck dissection limited to only the lymph node levels, which contain or at high risk for metastases, can offer very good regional control rates. Recent studies have clearly demonstrated that level IIB and V can be left undissected in the majority of head and neck cancers. There is also evidence that level IV dissection can be omitted in some patients. These modifications help to avoid complications such as spinal accessory nerve dysfunction or chylous fistula. On the other hand, for some patients, lymph node levels which are not routinely dissected during neck dissection, such as level VI or retropharyngeal lymph nodes need to be addressed to achieve regional control. Head and neck cancer is not a homogenous disease and neck dissection has to be individualized every patient. This requires a thorough knowledge of embryology, anatomy and pattern of lymphatic drainage for every anatomic subsite and clinical behaviour of cancer originating in these subsites.

The very recent classification of neck dissection proposed by Ferlito and colleagues offers a big flexibility and apparently will soon gain worldwide acceptance.

\section{Acknowledgment}

I would like to thank to my teachers in Uludag University School of Medicine Department of Otolaryngology, Professors Metin Arat, Ilker Tezel, Ibrahim Hizalan, Selcuk Onart and Levent Erisen, for teaching and supporting me since the time I started my residency training in the department.

\section{References}

Andersen PE, Warren F, Spiro J, Burningham A, Wong R, Wax MK, Shah JP, Cohen JI. Results of selective neck dissection in management of the node-positive neck. Arch Otolaryngol Head Neck Surg. 2002 Oct;128(10):1180-4.

Armstrong JG, Harrison LB, Thaler HT, et al: The indications for elective treatment of the neck in cancer of the major salivary glands. Cancer 1992; 69:615-619.

Armstrong WB, Netterville JL: Anatomy of the larynx, trachea, and bronchi. Otolaryngol Clin North Am 1995; 28:685-699.

Ayad T, Guertin L, Soulières D, Belair M, Temam S, Nguyen-Tân PF. Controversies in the management of retromolar trigone carcinoma. Head Neck. 2009 Mar;31(3):398-405.

Aydogan LB, Aydogan FK, Uguz A, et al. Levels IIB and IV in- volvement in laryngeal carcinoma. Final Program and Abstract Book, 6th International Conference on Head Neck Cancer, Washington, DC, 2004: 111 (poster session 1, p 1-195)

Bajwa MS, McMillan R, Khattak O, Thomas M, Krishnan OP, Webster K. Neck recurrence after level I-IV or I-III selective neck dissection in the management of the clinically N0 neck in patients with oral squamous cell carcinoma. Head Neck. 2011 Mar;33(3):403-6. 
Bhattacharyya N, Fried MP: Nodal metastasis in major salivary gland cancer: predictive factors and effects on survival. Arch Otolaryngol Head Neck Surg 2002; 128:904-908.

Brazilian Head and Neck Cancer Study Group. Results of a prospective trial on elective modified radical classical versus supraomohyoid neck dissection in the management of oral squamous carcinoma. Am J Surg. 1998 Nov;176(5):422-7.

Byers RM, Weber RS, Andrews T, McGill D, Kare R, Wolf P. Frequency and therapeutic implications of "skip metastases" in the neck from squamous carcinoma of the oral tongue. Head Neck 1997;19:14-9.

Byers RM. (1985). Modified neck dissection. A study of 967 cases from 1970 to 1980. Am J Surg, Vol. 150, No. 4, (October 1985), pp. (414-421), ISSN 0002-9610

Candela FC, Kothari K, Shah JP. Patterns of cervical node metastases from squamous carcinoma of the oropharynx and hypopharynx. Head Neck. 1990 MayJun;12(3):197-203.

Cannady SB, Lee WT, Scharpf J, Lorenz RR, Wood BG, Strome M, Lavertu P, Esclamado RM, Saxton JP, Adelstein DJ. Extent of neck dissection required after concurrent chemoradiation for stage IV head and neck squamous cell carcinoma. Head Neck. 2010 Mar;32(3):348-56.

Celik B, Coskun H, Kumas FF, Irdesel J, Zarifoglu M, Erisen L, Onart S. Accessory nerve function after level 2b-preserving selective neck dissection. Head Neck. 2009 Nov;31(11):1496-501.

Coskun HH, Erisen L, Basut O. Selective neck dissection for clinically N0 neck in laryngeal cancer: is dissection of level IIb necessary? Otolaryngol Head Neck Surg 2004;131:655-659.

De Zinis LO, Bolzoni A, Piazza C, Nicolai P. Prevalence and localization of nodal metastases in squamous cell carcinoma of the oral cavity: role and extension of neck dissection. Eur Arch Otorhinolaryngol. 2006 Dec;263(12):1131-5.

Dhiwakar M, Robbins KT, Rao K, Vieira F, Malone J. Efficacy of selective neck dissection for nodal metastasis with involvement of nonlymphatic structures.Head Neck. 2011 Aug;33(8):1099-105

Dhiwakar M, Robbins KT, Vieira F, Rao K, Malone J. Selective neck dissection as an early salvage intervention for clinically persistent nodal disease following chemoradiation. Head Neck. 2011 Apr 5. doi: 10.1002/hed.21707. [Epub ahead of print]

Dias FL, Lima RA, Kligerman J, Farias TP, Soares JR, Manfro G, Sa GM. Relevance of skip metastases for squamous cell carcinoma of the oral tongue and the floor of the mouth. Otolaryngol Head Neck Surg. 2006 Mar;134(3):460-5.

Ebrahimi A, Moncrieff MD, Clark JR, Shannon KF, Gao K, Milross CG, O'Brien CJ. Predicting the pattern of regional metastases from cutaneous squamous cell carcinoma of the head and neck based on location of the primary. Head Neck. 2010 Oct;32(10):1288-94.

Elsheikh MN, Mahfouz ME, Elsheikh E. Level IIb lymph nodes metastasis in elective supraomohyoid neck dissection for oral cavity squamous cell carcinoma: a molecular-based study. Laryngoscope. 2005 Sep;115(9):1636-40.

Elsheikh MN, Ferlito A, Rinaldo A, Shaha AR, Khafif A, Coskun HH, Kowalski LP, Medina JE. Do pathologic and molecular analyses of neck dissection specimens justify the preservation of level IV for laryngeal squamous carcinoma with clinically negative neck? J Am Coll Surg. 2006 Feb;202(2):320-3.

Elsheikh MN, Mahfouz ME, Salim EI, Elsheikh EA. Molecular assessment of neck dissections supports preserving level IIB lymph nodes in selective neck dissection 
for laryngeal squamous cell carcinoma with a clinically negative neck. ORL J Otorhinolaryngol Relat Spec 2006;68:177-184.

Erisen L, Basel B, Coskun H, et al. Evaluation of the number of lymph nodes dissected and neck recurrences in comprehensive and selective neck dissections. Kulak Burun Bogaz Ihtis Derg 2001;8:391-6 [Turkish].

Erisen L, Basel B, Irdesel J, et al. Shoulder function after accessory nerve-sparing neck dissections. Head Neck. 2004 Nov;26(11):967-71.

Fakih AR, Rao RS, Borges AM, Patel AR. Elective versus therapeutic neck dissection in early carcinoma of the oral tongue. Am J Surg 1989;158:309 - 313

Fasunla AJ, Greene BH, Timmesfeld N, Wiegand S, Werner JA, Sesterhenn AM. A metaanalysis of the randomized controlled trials on elective neck dissection versus therapeutic neck dissection in oral cavity cancers with clinically node-negative neck. Oral Oncol. 2011 May;47(5):320-4.

Ferlito A, Buckley JG, Shaha AR, et al. Rationale for selective neck dissection in tumors of upper aerodigestive tract. Acta Otolaryngol 2001;121:548-55.

Ferlito A, Shaha AR, Rinaldo A, et al: Management of clinically negative cervical lymph nodes in patients with malignant neoplasms of the parotid gland. ORL; J Otorhinolaryngol Rel Spec 2001; 63:123-126.

Ferlito, A \& Rinaldo, A. (2004). Osvaldo Suarez: Often-Forgotten father of Functional Neck Dissection (in the Non-Spanish-Speaking Literature. Laryngoscope, Vol. 114, No. 7, (July 2004), pp. (1177-1178), ISSN 1531-4995

Ferlito A, Rinaldo A, Silver CE, et al: Effective and therapeutic selective neck dissection. Oral Oncol 2006; 42:14-25.

Ferlito A, Silver CE, Rinaldo A. Selective neck dissection (IIA, III): a rational replacement for complete functional neck dissection in patients with N0 supraglottic and glottic squamous carcinoma. Laryngoscope. 2008 Apr;118(4):676-9.

Ferlito A, Corry J, Silver CE, Shaha AR, Thomas Robbins K, Rinaldo A. Planned neck dissection for patients with complete response to chemoradiotherapy: a concept approaching obsolescence. Head Neck. 2010 Feb;32(2):253-61.

Ferlito A, Robbins KT, Shah JP, Medina JE, Silver CE, Al-Tamimi S, Fagan JJ, et al. Proposal for a rational classification of neck dissections. Head Neck. 2011 Mar;33(3):445-50

Godden DR, Ribeiro NF, Hassanein K, Langton SG. Recurrent neck disease in oral cancer. J Oral MaxillofacSurg 2002;60:748 - 753.

Gold DR, Annino Jr DJ: Management of the neck in salivary gland carcinoma. Otolaryngol Clin North Am 2005; 38:99-105.

Hamming-Vrieze O, Balm AJ, Heemsbergen WD, Hooft van Huysduynen T, Rasch CR. Regional control of melanoma neck node metastasis after selective neck dissection with or without adjuvant radiotherapy. Arch Otolaryngol Head Neck Surg. 2009 Aug;135(8):795-800.

Jones AS, Roland NJ, Field JK, et al. The level of cervical lymph node metastases: their prognostic relevance and relationship with head and neck squamous carcinoma primary sites. Clin Otolar- yngol 1994;19:63-9.

Jones KR, Lodge-Rigal RD, Reddick RL, Tudor GE, Shockley WW. Prognostic factors in the recurrence of stage I and II squamous cell cancer of the oral cavity. Arch Otolaryngol Head Neck Surg 1992;118:483 - 485.

Kawata R, Koutetsu L, Yoshimura K, Nishikawa S, Takenaka H. Indication for elective neck dissection for N0 carcinoma of the parotid gland: a single institution's 20-year experience. Acta Otolaryngol. 2010 Feb;130(2):286-92. 
Kligerman J, Lima RA, Soares JR, et al. Supraomohyoid neck dissection in the treatment of T1/T2 squamous cell carcinoma of oral cavity. Am J Surg 1994;168:391 - 394.

Kowalski LP, Franco EL, de Andrade Sobrinho J. Factors influencing regional lymph node metastasis from laryngeal carcinoma. Ann Otol Rhinol Laryngol 1995;104:442-7.

Kowalski LP, Carvalho AL. Feasibility of supraomohyoid neck dissection in N1 and N2a oral cancer patients. Head Neck. 2002 Oct;24(10):921-4.

Koybasioglu A, Tokcaer AB, Uslu S, et al. Accessory nerve function after modified radical and lateral neck dissections. Laryngoscope 2000;110:73-7.

Koybasioglu A, Uslu S, Yilmaz M, et al. Lymphatic metastasis to the supraretrospinal recess in laryngeal squamous cell carcinoma. Ann Otol Rhinol Laryngol 2002;111:96-99.

Lea J, Bachar G, Sawka AM, Lakra DC, Gilbert RW, Irish JC, Brown DH, Gullane PJ, Goldstein DP. Metastases to level IIb in squamous cell carcinoma of the oral cavity: a systematic review and meta-analysis. Head Neck. 2010 Feb;32(2):184-90.

Lim YC, Lee JS, Koo BS, Choi EC. Level IIb lymph node metastasis in laryngeal squamous cell carcinoma. Laryngoscope 2006;116:268-272.

Lim YS, Lee JC, Lee YS, Lee BJ, Wang SG, Son SM, Kim IJ. Lateral cervical lymph node metastases from papillary thyroid carcinoma: predictive factors of nodal metastasis. Surgery. 2011 Jul;150(1):116-21.

Lodder WL, Sewnaik A, den Bakker MA, Meeuwis CA, Kerrebijn JD. Selective neck dissection for $\mathrm{N} 0$ and $\mathrm{N} 1$ oral cavity and oropharyngeal cancer: are skip metastases a real danger? Clin Otolaryngol. 2008 Oct;33(5):450-7.

Medina JE, Ferlito A, Robbins KT, Silver CE, Rodrigo JP, de Bree R, Rinaldo A, Elsheikh MN, Weber RS, Werner JA. Central compartment dissection in laryngeal cancer. Head Neck. 2011 May;33(5):746-52.

Mishra P, Sharma AK. A 3-year study of supraomohyoid neck dissection and modified radical neck dissection type I in oral cancer: with special reference to involvement of level IV node metastasis. Eur Arch Otorhinolaryngol. 2010 Jun;267(6):933-8.

Oskam IM, Hoebers F, Balm AJ, van Coevorden F, Bais EM, Hart AM, van den Brekel MW. Neck management in medullary thyroid carcinoma. Eur J Surg Oncol. 2008 Jan;34(1):71-6.

Paleri V, Kumar Subramaniam S, Oozeer N, Rees G, Krishnan S. Dissection of the submuscular recess (sublevel $\mathrm{IIb}$ ) in squamous cell cancer of the upper aerodigestive tract: prospective study and systematic review of the literature. Head Neck. 2008 Feb;30(2):194-200.

Pentenero M, Gandolfo S, Carrozzo M. Importance of tumor thickness and depth of invasion in nodal involvement and prognosis of oral squamous cell carcinoma: a review of the literature. Head Neck. 2005 Dec;27(12):1080-91.

Po Wing Yuen A, Lam KY, Lam LK, Ho CM, Wong A, Chow TL, Yuen WF, Wei WI. Prognostic factors of clinically stage I and II oral tongue carcinoma-A comparative study of stage, thickness, shape, growth pattern, invasive front malignancy grading, Martinez-Gimeno score, and pathologic features. Head Neck. 2002 Jun;24(6):513-20.

Razfar A, Walvekar RR, Melkane A, Johnson JT, Myers EN. Incidence and patterns of regional metastasis in early oral squamous cell cancers: feasibility of submandibular gland preservation. Head Neck. 2009 Dec;31(12):1619-23.

Regis De Brito Santos I, Kowalski LP, Cavalcante De Araujo V, etal: Multivariate analysis of risk factors for neck metastases in surgically treated parotid carcinomas. Arch Otolaryngol Head Neck Surg 2001; 127:56-60. 179. 
Rinaldo A, Elsheikh MN, Ferlito A, et al. Prospective studies of neck dissection specimens support preservation of sublevel IIB for laryngeal squamous carcinoma with clinically negative neck. J Am Coll Surg. 2006 Jun;202(6):967-70.

Robbins KT, Medina JE, Wolfe GT, Levine PA, Sessions RB, Pruet CW: Standardizing neck dissection terminology. Official report of the Academy's Committee for Head and Neck Sur- gery and Oncology. Arch Otolaryngol Head Neck Surg 1991, 117:601-605.

Robbins KT, Clayman G, Levine PA, et al. American Head and Neck Society. American Academy of Otolaryngology-Head and Neck Surgery. Neck dissection classification update: revisions proposed by the American Head and Neck Society and the American Academy of Otolaryngology-Head and Neck Surgery. Arch Otolaryngol Head Neck Surg 2002;128:751-8.

Ross GL, Soutar DS, MacDonald DG, Shoaib T, Camilleri IG, Robertson AG. Improved staging of cervical metastases in clinically node-negative patients with head and neck squamous cell carcinoma. Ann Surg Oncol 2004;11: 213 - 218.

Santos AB, Cernea CR, Inoue M, Ferraz AR. Selective neck dissection for node-positive necks in patients with head and neck squamous cell carcinoma: a word of caution. Arch Otolaryngol Head Neck Surg. 2006 Jan;132(1):79-81.

Sheahan P, O'Keane C, Sheahan JN, O'Dwyer TP. Effect of tumor thickness and other factors on the risk of regional disease and treatment of the N0 neck in early oral squamous carcinoma. Clin Otolaryngol 2003;28: 461 - 471.

Sparano A, Weinstein G, Chalian A, Yodul M, Weber R. Multivariate predictors of occult neck metastasis in early oral tongue cancer. Otolaryngol Head Neck Surg 2004; 131:472 - 476.

Spiro RH, Huvos AG, Wong GY, Spiro JD, Gnecco CA, Strong EW. Predictive value of tumor thickness in squamous carcinoma confined to the tongue and floor of the mouth. Am J Surg 1986;152:345 - 350.

Spiro RH: Salivary neoplasms: overview of a 35-year experience with 2,807 patients. Head Neck Surg 1986; 8:177-184.

Uppaluri, R \& Sunwoo, JB. (2010). Neoplasms of the Hypopharynx and Cervical Esophagus, In : Cummings Otolaryngology Head \& Neck Surgery, Flint PW, Haughey BH, Lund VJ, Niparko JK, Richardson MA, Thomas JR, pp. 1177-1230, Mosby Elsevier, ISBN 978-0-323-05283-2, Philadelphia.

Villaret AB, Piazza C, Peretti G, Calabrese L, Ansarin M, Chiesa F, Pellini R, Spriano G, Nicolai P. Multicentric prospective study on the prevalence of sublevel IIb metastases in head and neck cancer. Arch Otolaryngol Head Neck Surg. 2007 Sep;133(9):897-903.

Weber RS, Marvel J, Smith P, et al: Paratracheal lymph node dissection for carcinoma of the larynx, hypopharynx, and cervical esophagus. Otolaryngol Head Neck Surg 1993; 108:11.

Woolgar JA. T2 carcinoma of the tongue: the histopathologist's perspective. Br J Oral Maxillofac Surg 1999;37: 187 - 193.

Woolgar JA. Salvage neck dissections in oral and oropharyngeal squamous cell carcinoma: histological features in relation to disease category. Int J Oral Maxillofac Surg. 2006 Oct;35(10):907-12.

Yu GY, Ma DQ: Carcinoma of the salivary gland: a clinicopathologic study of 405 cases. Semin Surg Oncol 1987; 3:240-244.

Zhang L, Zhu YX, Wang Y, Huang CP, Wu Y, Ji QH. Salvage surgery for neck residue or recurrence of nasopharyngeal carcinoma: a 10-year experience. Ann Surg Oncol. 2011 Jan;18(1):233-8 


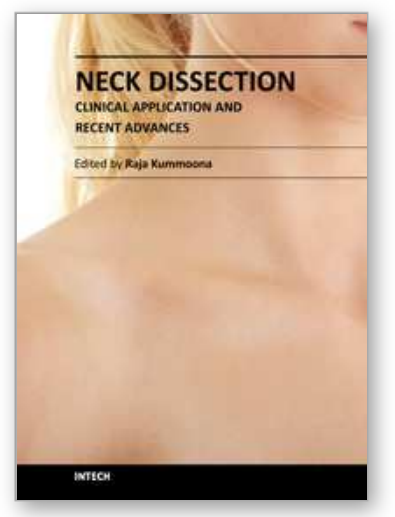

\author{
Neck Dissection - Clinical Application and Recent Advances \\ Edited by Prof. Raja Kummoona
}

ISBN 978-953-51-0104-8

Hard cover, 164 pages

Publisher InTech

Published online 22, February, 2012

Published in print edition February, 2012

Neck Dissection - Clinical Application and Recent Advances is a leading book in neck surgery and represents the recent work and experiences of a number of top international scientists. The book covers all techniques of neck dissection and the most recent advances in neck dissection by advocating better access to all techniques of neck dissection; e.g. Robotic surgery (de Venice) system, a technique for detection of lymph node metastasis by ultra sonography and CT scan, and a technique of therapeutic selective neck dissection in multidisciplinary treatment. This book is essential to any surgeon specializing or practicing neck surgery, including Head Neck Surgeons, Maxillofacial Surgeons, ENT Surgeons, Plastic and Reconstructive Surgeons, Craniofacial Surgeons and also to all postgraduate Medical \& Dental candidates in the field.

\title{
How to reference
}

In order to correctly reference this scholarly work, feel free to copy and paste the following:

H. Hakan Coskun (2012). Current Concept of Selective Nek Dissection, Neck Dissection - Clinical Application and Recent Advances, Prof. Raja Kummoona (Ed.), ISBN: 978-953-51-0104-8, InTech, Available from: http://www.intechopen.com/books/neck-dissection-clinical-application-and-recent-advances/current-conceptof-selective-neck-dissection

\section{INTECH}

open science | open minds

\section{InTech Europe}

University Campus STeP Ri Slavka Krautzeka 83/A

51000 Rijeka, Croatia Phone: +385 (51) 770447

Fax: +385 (51) 686166

www.intechopen.com

\author{
InTech China \\ Unit 405, Office Block, Hotel Equatorial Shanghai \\ No.65, Yan An Road (West), Shanghai, 200040, China \\ 中国上海市延安西路65号上海国际贵都大饭店办公楼405单元 \\ Phone: +86-21-62489820 \\ Fax: $+86-21-62489821$
}


(C) 2012 The Author(s). Licensee IntechOpen. This is an open access article distributed under the terms of the Creative Commons Attribution 3.0 License, which permits unrestricted use, distribution, and reproduction in any medium, provided the original work is properly cited. 